\title{
Scientific Analysis or Political Ideology?
}

\author{
Richard F. Rakos \\ Cleveland State University
}

Unfortunately, space does not permit an extended reply to Joe Morrow and Jerry Ulman; such a response will be forthcoming in a future paper. However, a few brief comments are warranted at this time.

First, reductionism is appropriate when theoretical continuity exists between the higher and lower level theories (Nagel, 1961). The formal requirement for reduction is that all theoretical expressions in the higher order theory must connect with expressions in the more basic theory (Nagel, 1961; Turner, 1965). The concepts of the metacontingency (upon which Ulman relies) and of contingencies of reinforcement meet this test. And unfortunately, the planned metacontingencies of socialism have failed to increase the frequency of desired behavior - in my assessment, due to the influence of behavioral processess affecting individuals (leaders, managers, workers, farmers, etc.).

Second, we can explain socialism's problems by blaming bureaucratic ossification and capitalistic interference, and argue that "true" socialism has not been implemented - but does that really explain anything? We can just as easily explain capitalism's many failures as due to "greed" and assert that "benevolent capitalism" has not been fostered. But these are simply "explanatory fictions" (Skinner, 1971): the more interesting and complete explanations involve the reasons why the bureaucracy exists and is maintained and why people emit greedy responses. Toward this end, a reductionistic analysis of individual behavior in the context of socio-historical environmental conditions is a powerful conceptual tool that can help illuminate the reasons. Such an analysis, however, will be unlikely to identify the reasons why the phenomenon initially developed. Thus, while it is true (as Ulman notes) that group consequences rather than individual consequences are responsible for the evolution of the culture, a reductionistic analysis can nevertheless help us identify the functional and dysfunctional elements of that culture.

Finally, we do not know the extent to which rules, delayed reinforcers, and values (moral incentives) - upon which socialism relies for its control of behavior - can shape and maintain behavior in an environment that prompts and immediately materially reinforces incompatible behavior.
However, observational data and the bulk of behavioral research suggest that the potency of material reinforcers is weakened only in environments that establish extensive and systematic controls. Socialism, therefore, requires a highly controlled social- political-economic environment, but such an arrangement is no longer possible due to the extensive technological sophistication of the world. Technology through increased travel, media exposure, education, and industrial production - conditions an exceptionally wide variety of secondary reinforcers and behavioral competencies. No system today can exert the control that is required to prevent these conditioning processes from occuring. Furthermore, the current environment is an enriched (as opposed to barren) one, which will reduce the ability of socialism's limited and delayed reinforcers to support a high response rate (Herrnstein, 1970). This environment will also foster the development of stimulus equivalence classes between money and a wide range of material and service reinforcers (cf. Hayes, 1987). The consequence of this technological environment, therefore, is a world that cannot be adequately controlled to prevent material incentives from gaining primary influence over behavioral repertoires that are continually increasing in range, diversity, and competence. Even Cuba, the example cited by Ulman, has found it necessary to utilize material incentives (Brundenius, 1984; MacEwan, 1981).

These issues require - and will receive - a more extensive analysis. However, in the meantime, it is important to recognize that my argument is not intended to be antisocialistic. I am simply asserting that we must employ scientific analyses rather than political ones, since in the long run, a more equitable and just society will depend more on empricism than on ideology (Skinner, 1971).

\section{References}

Brundenius, C. (1984). Revolutionary Cuba: The challenge of economic growth with equity. Boulder, Co.: Westview Press.

Hayes, S.C. (1987). Language and the incompatibility of evolutionary and psychological continuity. Behavior Analysis, 22, 49-54.

MacEwan, A. (1981). Revolution and economic development in Cuba. New York: St. Martin's Press.

Nagel, E. (1961). The structure of science: Problems in the logic of scientific explanation. New York: Harcourt, Brace \& World.

Skinner,B.F. (1971). Beyond freedom and dignity. New York: Bantam/ Vintage.

Turner, M.B. (1965). Philosophy and the science of behavior. New York: Appleton-Century-Crofts. 